\title{
Control of Nitrogen Oxides in Diesel Engine Exhaust by Catalytic Reduction
}

\author{
P. V. Krishna Murthy ${ }^{1}$, M. V. S. Murali Krishna ${ }^{2}$, \\ ${ }^{I}$ Vivekananda Institute of Science and Information Technology, Shadnagar, Mahabubnagar-509216 \\ ${ }^{2,}$ Department of Mechanical Engineering, Chaitanya Bharathi Institute of Technology, Gandipet, Hyderabad- 500075,
}

\begin{abstract}
The nitrogen oxides (NOx) are prominent and harmful pollutants in the exhaust of diesel engines. The reduction of NOx to harmless products using catalysts is proved to be a remedy. The present study attempts to reduce NOx emissions in the exhaust of low heat rejection (LHR) diesel engine by catalytic reduction, using lanthanum ion exchanged zeolite (catalyst-A) and urea infused lanthanum ion exchanged zeolite (catalyst-B) under varied conditions . The effect of temperature of catalyst, space velocity, and void ratio on the reduction of NOx in the exhaust of the engines are also studied and compared with the conventional engine (CE) under identical conditions. The study showed a considerable reduction by $\mathbf{4 0 - 5 0 \%}$ in NOx emissions.
\end{abstract}

Key Words: Nitrogen oxides, diesel engine, LHR engine, exhaust, catalytic reduction

\section{I.INTRODUCTION}

The emissions from diesel engines largely contribute to atmospheric pollution and health problems in human beings [1-3] and other animals [4]. The nitrogen oxides (NOx) are most common and harmful pollutants in the exhaust of diesel engines besides CO. The NOx play an important role in atmospheric reactions which create harmful particulate matter, smog, acid rains etc [5]. Breathing of NOx causes respiratory illness, bronchitis, eye irritation and carcinogenic effects $[1,5,6]$. The control of NOx has been achieved by the improvements in the engine design and combustion chamber modifications etc. But most of those modifications resulted in increase of pollution by particulate emissions $[7,8]$ and deterioration of fuel economy [9].

The selective catalytic reduction technique $[10,11]$ is becoming increasingly popular and cost effective method in reduction of NOx levels. The modified zeolites [12-15] are cheaper and can reduce NOx over wide range of airfuel ratios and temperature. For effective combustion of fuel, high temperature is required in combustion chamber of the engine, which is provided by an insulated or LHR version of engine. The present paper reports the comparative study of measurement and control of NOx in the exhaust of conventional and low heat rejection (LHR) diesel engines by using lanthanum ion exchanged zeolite and urea infused catalysts.

\section{EXPERIMENTAL PROGRAMME}

Figure 1 shows the schematic diagram of experimental set up employed in the study. Investigations are carried out on a Kirloskar make, single cylinder, medium speed, water cooled, $3.68 \mathrm{~kW}$ diesel engine. It is connected to an electrical dynamometer for measuring brake power of the engine from which brake mean effective pressure (BMEP) is calculated. The load on the dynamometer is varied by means of loading rheostat. The exhaust gas temperature is measured by using iron and iron- constantan thermocouple. NOx levels in the exhaust of the engine are measured by using Netel Chromatograph NOx analyzer, which is connected to the outlet of catalytic chamber, which in turn connected to the exhaust pipe of the engine. The rate of gas flow is measured by using a rotometer.

The catalyst is prepared [10] by using zeolite and lanthanum ion salt. Ion exchange is done by stirring 500 grams of zeolite in a $2 \mathrm{~N}$ solution of lanthanum (III) salt for 5-6 hours at $70-80^{\circ} \mathrm{C}$. Ion exchanged zeolite is recovered by filtration and activated by calcination in an oven at $400^{\circ} \mathrm{C}$ for $\quad 3$ hours and is furnace cooled to retain mechanical properties. Modified zeolite so obtained is placed in catalytic chamber which has a cylindrical shape with a diameter of $100 \mathrm{~mm}$ and length $250 \mathrm{~mm}$. Infusion of urea on lanthanum exchanged zeolite (catalyst-B) is made by gravity feed dosing system. A nozzle is used to generate fine spray of urea solution into exhaust gas before it enters into catalytic chamber containing lanthanum exchanged zeolite. LHR engine $[16,17]$ consists of an air gap insulated piston with superni crown and air gap insulated liner with superni insert as shown in Fig.2.

\section{RESULTS AND DISCUSSION}

A comparative data pertaining to NOx emissions in the exhaust of the engine under varied conditions is presented in Table-1.The data shows that the extent of NOx emissions is higher when no catalyst is used. Higher levels of NOx emissions in LHR engine in comparison with CE are due to the high temperatures in the combustion chamber leading to formation of high NOx levels by oxidation of nitrogen by oxygen. The presence of catalysts (A and B) have significantly reduced NOx levels in the exhaust of the engines. The hydrolysis of urea in catalyst$\mathrm{B}$ gives ammonia which also reduces NOx to nitrogen. A decline in percentage reduction of NOx content with 
catalyst-B on LHR version of the engine compared to $\mathrm{CE}$ can be due to dissociation of urea at higher temperature.

The variation of NOx reduction efficiency with void ratio is shown in Fig.3. The parameter, void ratio is given by volume occupied by catalyst to volume of catalytic chamber. The catalysts are more efficient in NOx reduction at a void ratio of 0.6 , beyond which a declination in catalytic activity is observed. This can be due to reduction in extent of exposure of catalyst to the exhaust gases. The variation of NOx levels with BMEP on CE and LHR versions of the engine using Catalyst $-\mathrm{A}$ and Catalyst-B is shown in Fig.4. From the figure, it can be observed that NOx levels increase with increase of BMEP of the engine. This is due to increase of combustion temperature with $\mathrm{BMEP}$, resulting in formation of more NOx form nitrogen and oxygen in the combustion chamber. Under full load conditions of the engine, when catalyst-A is used, a reduction in NOx levels by $30 \%$ is observed on CE and $55 \%$ on LHR engine.

The variation of NOx reduction efficiency with catalyst temperature on CE and LHR engine at peak load operation is shown in Figure 5. On CE version of the engine, with catalyst-A, the reduction efficiency increases from 40 to $50 \%$ at $300^{\circ} \mathrm{C}$ and when the catalyst temperature is increased to $400^{\circ} \mathrm{C}$ the reduction efficiency decreases to $30 \%$. With catalyst-B, the reduction in NOx levels is maximum $(60 \%)$ at catalyst temperature of $175^{\circ} \mathrm{C}$ and beyond which the reduction efficiency decreases. On LHR version of the engine, when catalyst-A is used, NOx reduction efficiency increases from 57 to $70 \%$ with increase in catalyst temperature from room temperature to $300^{\circ} \mathrm{C}$. With catalyst-B, the NOx reduction efficiency increases from 40 to $50 \%$, with increase in catalyst temperature from room temperature to $175^{\circ} \mathrm{C}$ and further increment in temperature decreases the efficiency of the catalyst. Thus higher temperature of exhaust gases of LHR version of the engine and higher temperature of catalyst causes decomposition of urea leading to decrease in NOx reduction efficiency. The variation of NOx levels with space velocity on both versions of the engine using catalyst-B is shown in Fig.6. Space velocity is a ratio of exhaust gas flow rate in $\mathrm{m}^{3} / \mathrm{h}$ to the volume of catalytic chamber. The NOx reduction efficiency decreases when space velocity increases beyond $400 / \mathrm{h}$. This can be due to insufficient time for reduction reaction in presence of catalyst. The catalyst performance decreases with increase in space velocity and later it becomes constant at higher space velocities beyond $850 / \mathrm{h}$. Thus, the lanthanum based zeolite supports catalytic reduction of NOx levels in the exhaust.

\section{CONCLUSIONS}

1. The catalyst-A is more effective on LHR version of the engine in reducing NOx levels, while catalyst-B is more effective on conventional engine.

2. The catalysts show maximum efficiency in reduction of NOx levels at void ratio of 0.6.
3. The optimum space velocity for efficient reduction of NOx levels is found to be $450 / \mathrm{h}$.

4. The NOx levels increase with BMEP of the engines due to increase in combustion temperature.

5. The increase in catalyst temperature increases the NOx reduction efficiency upto certain level beyond which the efficiency decreases

6. About $40-50 \%$ decrease in NOx emissions can be observed by catalytic reduction.

\section{ACKNOWLEDGEMENTS}

The authors are thankful to authorities of Chaitanya Bharathi Institute of Technology, Hyderabad for the facilities provided to carry out this work.

\section{VI. .REFERENCES}

[1] A.C. Lloyd and T.A. Cackette , J. Air Waste Manag.Assoc., 51, 2001, 809-816.

[2] K. Mukhopadhyay and O. Forsell, Ecological Economics, 55, 2005. 235-242.

[3] M. Kampa and E. Castanas, Environ.Pollut., 151, 2008, 362-372.

[4] A.D. Wheatley and S. Sadhra, Ann.Occup.Hyg., 48, 2004, 369-380.

[5] D.L. Mauzerall, B. Sultan, N. Kim and D.F. Bradford, NBER Working Paper No.10824, 2004, http://www.nber.org.paper/w 10824.

[6] J.C. Summers, S.V. Houtte and D.Psaras, Applied Catalysis B, Environmental, 10, 1996, 139-145.

[7] O.A. Ledecke and D.L. Dimik, Diesel Exhaust Particulate Control System development, SAE Paper No 830085. 1983.

[8] J.S. McDonald and G.M. Simon, Development of particulate trap system for heavy duty diesel engine SAE Paper No.880008 (1988).

[9] P.P. Herzog. et al., NOx reduction strategies for DI diesel engine., SAE Paper No 920470 ,1992.

[10] B.B. Ghosh, and P.Nag, NOx reduction in S.I. engine exhaust using zeolite with urea infusion. Proc. $15^{\text {th }}$ National Conference I.C engines and combustion.Chennai, 1997, 357 - 362.

[11] B. Sandro, K. Oliver, T. Arno and A. Roderik, Catalysis Reviews, 50, 2008, 492-501.

[12] T.Yvonne, B.Beate and Weitkamp, Microporous and Mesoporous materials, 3(3), 1999.

[13] H. Lin and B.O Steven, Reduction of NOx in diesel exhaust of gases and fuel injection systems. US Patent 6919047, 2005.

[14] M. Weine, M.Hunger, M. Breuninger, H.K. Karge, and J.Weitkamp, J.Catalysis, 198, 2001, 256- 267.

[15] H.Y.Chen and W.M.H. Sachtler, Catlayst Letters,50, 1998, 125-137.

[16] D.A Parkar, and G.M. Dennison, The development of air gap insulated piston, SAE Paper No. 870652.1987.

[17] M.V.S Murali Krishna, Investigations on low heat rejection diesel engine with alternate fuels, Ph.D. Thesis, J.N.T. University. Hyderabad. 2004, 
TABLE 1

Data of $\%$ reduction of NOx emissions in different versions of the engine

\begin{tabular}{|c|c|c|c|c|}
\hline $\begin{array}{c}\text { Type of } \\
\text { Catalyst }\end{array}$ & $\begin{array}{c}\text { NOx } \\
\text { emissions } \\
\text { in CE } \\
\text { (ppm) }\end{array}$ & $\begin{array}{c}\text { \% of NOx } \\
\text { reduction } \\
\text { in CE }\end{array}$ & $\begin{array}{c}\text { NOx } \\
\text { emissions } \\
\text { in LHR } \\
\text { engine } \\
\text { (ppm) }\end{array}$ & $\begin{array}{c}\text { \% of NOx } \\
\text { reduction } \\
\text { in LHR } \\
\text { engine }\end{array}$ \\
\hline $\begin{array}{c}\text { No } \\
\text { catalyst }\end{array}$ & 850 & -- & 1300 & -- \\
\hline $\begin{array}{c}\text { Catalyst- } \\
\text { A }\end{array}$ & 510 & 40 & 560 & 57 \\
\hline $\begin{array}{c}\text { Catalyst- } \\
\text { B }\end{array}$ & 425 & 50 & 780 & 40 \\
\hline
\end{tabular}

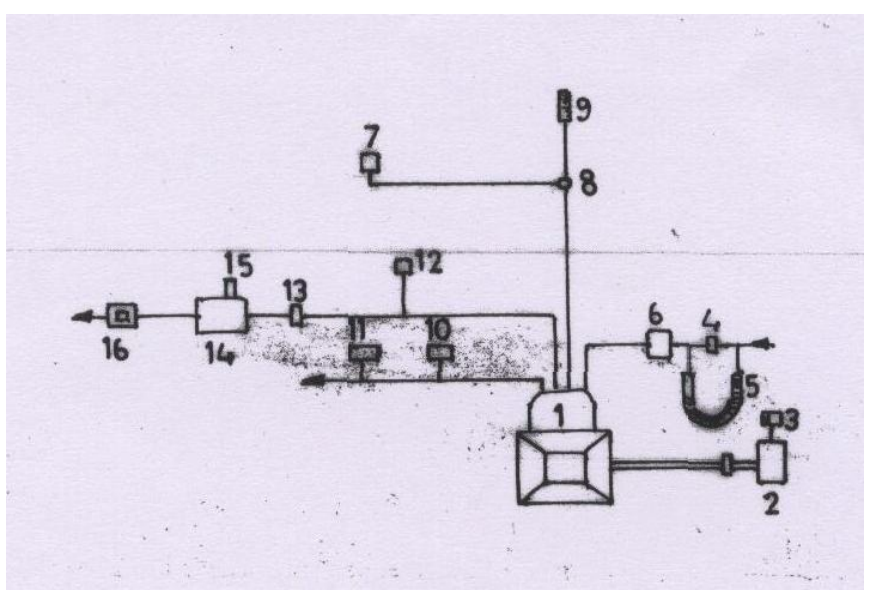

Fig.1 Experimental Set-up

1.Engine, 2. Electrical dynamometer, 3. Load box, 4. Orifice meter, 5. U-tube water manometer, 6. Air box, 7.Fuel tank, 8. Three-way valve, 9. Burette, 10. Outlet jacket water temperature indicator, 11. Outlet jacket water flow meter, 12. Exhaust gas temperature indicator, 13. Rotomter, 14. Catalytic chamber, 15. Nozzle, 16. Netel chromatograph NOx analyzer,

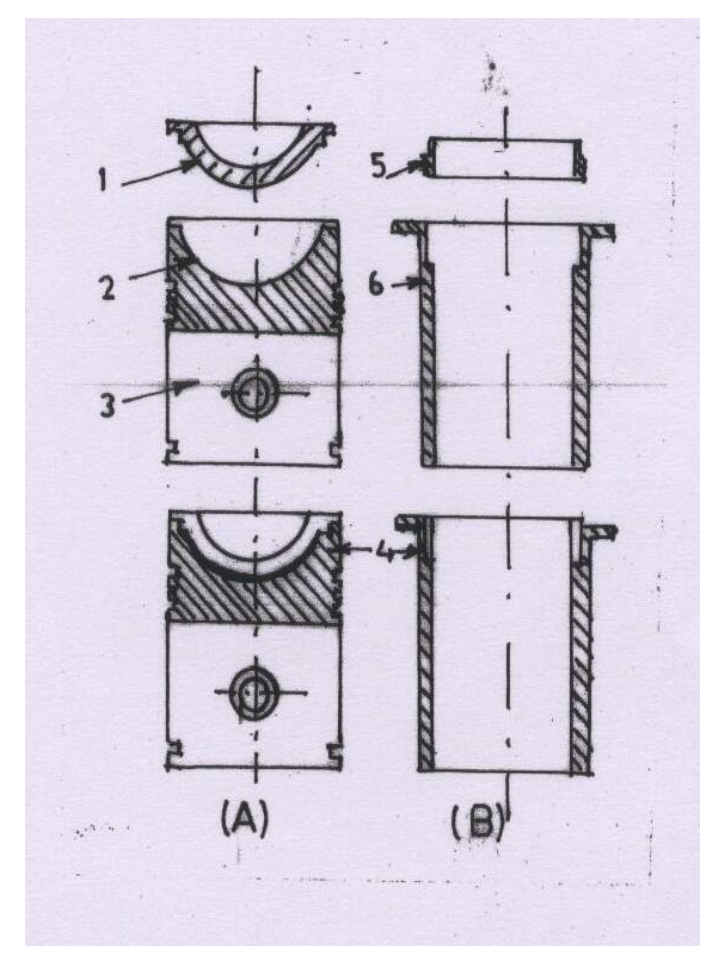

Fig. 2 Insulated Piston and liner assemblies

1 Superni crown, 2 Gasket, 3 Al. body of piston, 4Airgap, 5 Superni insert, 6 Liner body,

(A) Air gap insulated piston, (B) Air gap insulated liner 


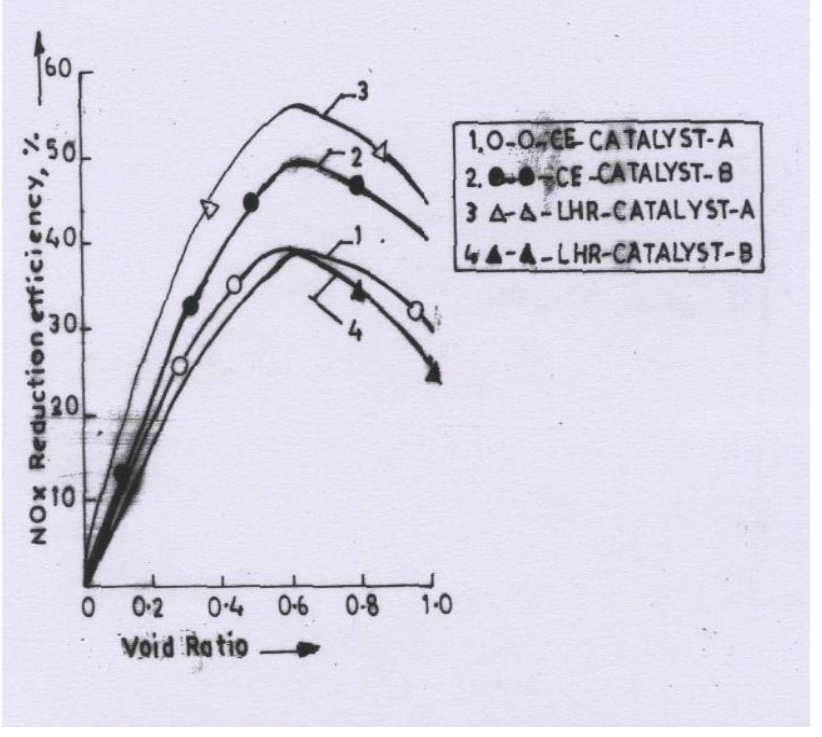

Fig. 3 Variation of NOx reduction efficiency with void Ratio

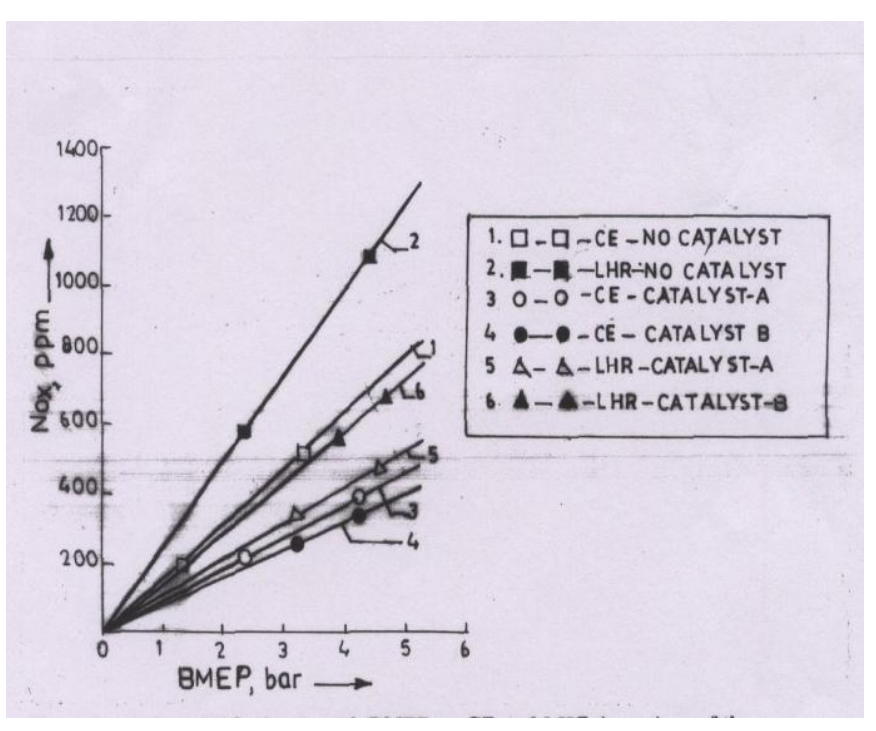

Fig. 4. Variation of NOx levels with BMEP on CE and LHR-1 versions of the engine using Catalyst $-\mathrm{A}$ and Catalyst-B.

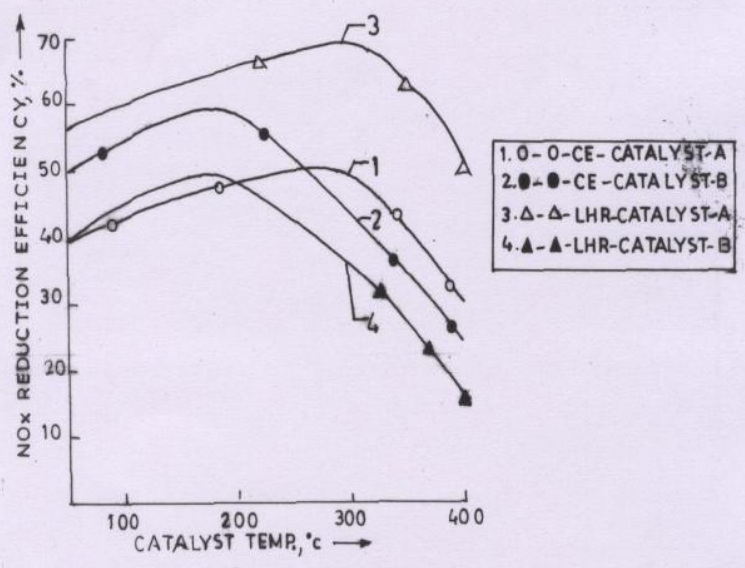

Fig.5. Variation of NOx reduction efficiency with catalyst temperature on CE and LHR-1 versions of the engine at peak load operation

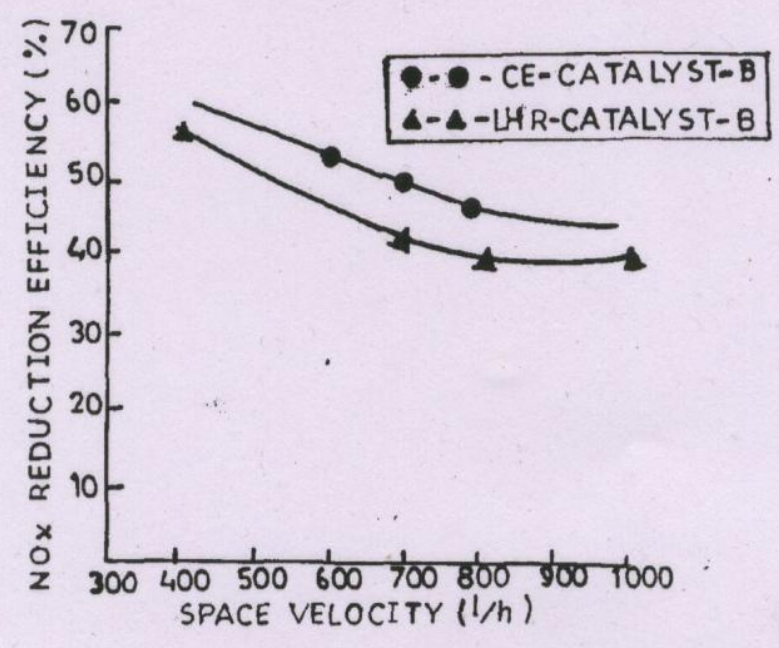

Fig 6. Variation of NOx levels with space velocity on CE and LHR-1 versions of the engine using catalystB 